\title{
An Arabidopsis Splicing RNP Variant STEP1 Regulates Telomere Length Homeostasis by Restricting Access of Nuclease and Telomerase
}

\author{
Hyun Hee Yoo, Chian Kwon ${ }^{1, *}$, and In Kwon Chung* \\ Departments of Biology and Integrated Omics for Biomedical Science, WCU Program, Yonsei University, Seoul 120-740, Korea, ${ }^{1}$ Department of \\ Molecular Biology, Brain Korea 21 Graduate Program for RNA Biology, Dankook University, Yongin 448-701, Korea \\ Received May 14, 2010; revised June 17, 2010; accepted June 18, 2010; published online August 23, 2010
}

In the article by Yoo et al. that appears in the journal, Mol. Cells, Vol. 30, No. 3, pp. 279-283, ACKNOWLEDGMENTS should be revised as written below.

\section{ACKNOWLEDGMENTS}

This work was supported by grants from the Korea Research Foundation [M1075604000107N560400110] and the Korean Ministry of Education, Science, and Technology through the WCU project [R31-2008-000-10086-0] to IKC. 